\title{
Field Study of the Interior Noise and Vibration of a Metro Vehicle Running on a Viaduct: A Case Study in Guangzhou
}

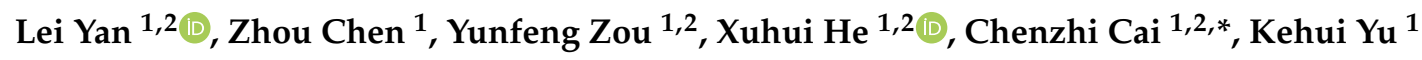 \\ and Xiaojie $\mathrm{Zhu}^{3}$ \\ 1 School of Civil Engineering, Central South University, Changsha 410075, China; leiyan@csu.edu.cn (L.Y.); \\ zhouchen520@csu.edu.cn (Z.C.); yunfengzou@csu.edu.cn (Y.Z.); xuhuihe@csu.edu.cn (X.H.); \\ 164801022@csu.edu.cn (K.Y.) \\ 2 National Engineering Laboratory for High Speed Railway Construction, Changsha 410075, China \\ 3 Guangzhou Metro Corporation, Ltd., Guangzhou 510000, China; zhuxiaojie@gzmtr.com \\ * Correspondence: chenzhi.cai@csu.edu.cn
}

Received: 11 March 2020; Accepted: 16 April 2020; Published: 19 April 2020

\begin{abstract}
The interior noise and vibration of metro vehicles have been the subject of increasing concern in recent years with the development of the urban metro systems. However, there still is a lack of experimental studies regarding the interior noise and vibration of metro vehicles. Therefore, overnight field experiments of the interior noise and vibration of a standard B-type metro train running on a viaduct were conducted on metro line 14 of Guangzhou (China). Both the A-weighted sound pressure level and linear sound pressure level were used to evaluate the interior noise signals in order to revel the underestimation of the low-frequency noise components. The results show that the interior noise concentrates in the low-to-middle frequency range. Increasing train speeds have significant effects on the sound pressure level inside the vehicle. However, two obvious frequency ranges $(125-250 \mathrm{~Hz}$ and $400-1000 \mathrm{~Hz}$ ) with respective corresponding center frequencies $(160 \mathrm{~Hz}$ and $800 \mathrm{~Hz}$ ) of the interior noise are nearly independent of train speed. The spectrum analysis of the vehicle body vibration shows that the frequency peak of the floor corresponds to the first frequency peak of the interior noise spectrum. There are two frequency peaks around $40 \mathrm{~Hz}$ and $160 \mathrm{~Hz}$ of the sidewall's acceleration level. The frequency peaks of the acceleration level are also independent of the train speeds. It hopes that the field measurements in this paper can provide a data set for researchers for further investigations and can contribute to the countermeasures for reducing interior noise and vibration of a metro vehicle.
\end{abstract}

Keywords: sound pressure level; field measurements; spectrum analysis; interior noise and vibration of vehicle

\section{Introduction}

In recent decades, the urban metro system has seen rapid development in eastern countries due to its fast speed, high efficiency, comfort, and environmental benefits, especially in China. According to recent statistics, the total length of China's operating metro lines has increased from $112 \mathrm{~km}$ among three cities in 2000 to about $6000 \mathrm{~km}$ among 41 cities in 2019. The elevated metro has become an alternative rather than the general underground metro type due to its low cost and short construction period, especially in a metropolis with a well-developed metro network, such as Beijing, Shanghai, and Guangzhou. The total length of operated elevated metros in China accounts for nearly a quarter of the whole $6000 \mathrm{~km}$ [1]. Although many benefits come from urban rail transit, the rail transit system has been considered the second greatest noise source affecting human modern lifestyles [2-4], after road 
traffic [5-7], but before airports [8,9], industries and wind turbines [10,11], and port activities [12,13]. Moreover, there are growing complaints about the noise inside the trains, as more passengers and metro staff will be exposed to interior train noise for a longer time with the expansion of the metro system $[14,15]$. According to statements released by the World Health Organization (WHO), noise exposure to $85 \mathrm{~dB}$ A-weighted over $45 \mathrm{~min}$ will lead to noise-induced hearing loss (NIHL) [16]. Meanwhile, recent investigations reveal that the accumulation of short-term noise exposure can also cause NIHL [17]. Furthermore, sleep disorders with awakenings, learning impairment, hypertension, ischemic heart disease and especially annoyance are the most common negative health effect related to prolonged exposure [18-21].

The interior noise inside a railway vehicle is composed of air-borne and structure-borne sound generated by exterior sources mainly including wheel-rail rolling effects, excitation phenomena due to the sleeper-passing frequency, and aerodynamic effects [22]. Many achievements concerning the interior noise problem of trains have been made theoretically and numerically. Eade and Hardy [23] investigated the transmission mechanisms of noise generated by various sources into a vehicle train through both the air-borne and structure-borne path. The spectrum results of interior noise show that low-frequency noise accounted for the largest proportion. Forssén et al. [24] proposed a statistical energy analysis model to predict the interior sound field of a railway vehicle. The prediction results were validated by a ray tracing method and scale model measurements. Zheng et al. [25] established a full-spectrum prediction method of the interior noise of high-speed train by considering both the air-borne and structural-borne noise. Dai et al. [26] presented a prediction method by applying statistical vibration and acoustic energy flow to obtain the full-spectrum interior noise of high-speed railway vehicles. Shi [27] employed a dynamic train-track interaction model, a finite element model, and an acoustic boundary element model to predict the interior noise of a high-speed vehicle at a speed of $200 \mathrm{~km} / \mathrm{h}$.

In addition to the aforementioned theoretical and numerical investigations, many field measurements have also been conducted. Han et al. [28] investigated the effects of rail corrugation on the interior noise and vibration of a metro vehicle based on the measurements. Li et al. [29] conducted field measurements to examine the interior noise and vibration of a railway vehicle at different speeds with respect to two different rail fastener stiffnesses. Fan et al. [30] analyzed the major interior noise sources and their corresponding transmission path into a high-speed vehicle through acoustic-vibration measurements as the train travels. Thompson [22] concluded that the low-frequency noise in a trail vehicle were the results of the structure-borne noise, while the air-borne noise contributed to the high-frequency noise of the train's interior noise according to measured results in British coaches. Conventionally, the A-weighted sound pressure level (SPL) has been widely used to evaluate the acoustical environment inside the train, and it has already been incorporated into some standards [31,32]. However, acoustic comfort inside the train cannot be achieved even when the A-weighted SPL inside the train meets the requirements of these standards due to the underestimated impacts of the low-frequency components of interior noise on people in the A-weighted SPL evaluation [33,34]. Soeta et al. [35] pointed out that the improvement of the acoustic environment in a train's carriages only through the reduction of the A-weighted SPL inside the carriage was impossible. The subjective felling should be considered in the evaluation of acceptable interior noise inside a train vehicle [22,36].

As there remains great concern regarding the acoustic environment of a metro vehicle, the lack of experimental studies about the interior noise and vibration of a metro vehicle, let alone investigations concerning a metro vehicle running on a viaduct, is noticeable. Moreover, with the trend of lighter trains and higher speeds, the increase of both air-borne and structure-borne sound will lead to the deterioration of the acoustic environment of a metro vehicle. This paper aims to determine the characteristics of the interior noise and vibration of a metro vehicle running on a viaduct. The measurements of vibration and noise were conducted in the standard B-type metro train on metro line 14 in Guangzhou (China). In order to analyze the underestimated effects of low-frequency noise components inside the vehicle, both the A-weighted SPL and linear SPL were adopted to evaluate 
the measured interior noise signals. The relationships between the interior noise and the vibration of the metro vehicle under various train speeds were investigated. The main noise sources of the metro vehicle were identified through the spectrum analysis of the measured vibration acceleration signals. The field measurements here can provide an available data set for researchers for further investigations, and could contribute to countermeasures for reducing interior noise and vibration of a metro vehicle.

\section{Description of the Measurements}

The main sources of interior noise can propagate by both air-borne and structure-borne paths, which includes rolling noise related to wheel and track characteristics and roughness and aerodynamic noise related to train speed and train type. The coupling effects of the train-track-bridge system may also affect the sources of interior noise when the metro vehicle is running on a viaduct [22]. The data analysis methods and the detailed measurements procedures are described here.

\subsection{Data Analysis Methods}

The total sound pressure level is a simple and direct parameter to quantify the sound level, which is defined in terms of the time-varying sound pressure level, as follows:

$$
S P L=10 \log _{10}\left[\frac{1}{T} \int_{0}^{T} 10^{L(t) / 10} d t\right]
$$

where $T$ is the required period of time and $L(t)$ is the sound pressure level at time $t$. This descriptor is a linear (i.e., unweighted) single value of sound level. In order to approximate the response of the human ear at low sound levels, the A-weighted total sound pressure level has been proposed and has been adopted in some international and Chinese standards. The A-weighted sound pressure level is defined as

$$
S P L_{A}=10 \log _{10}\left[\frac{1}{T} \int_{0}^{T} 10^{L_{P A}(t) / 10} d t\right]
$$

where $L_{P A}(t)$ is the A-weighted sound pressure level at time $t$ according to the A-weighted circuit.

The fast Fourier transform (FFT) is one of the most important numerical algorithms and has been widely used in signal analysis. The original signals can be transformed from the time domain to the frequency domain by adopting the FFT. Then, the spectral characteristics of the signals can be extracted. The FFT could be expressed as [37]

$$
X(k)=\sum_{n=0}^{N-1} x(n) W_{N}^{k n}
$$

where $N$ represents the order number of each harmonic component, $x(n)$ represents the generic harmonic component as a complex number, $W_{N}=e^{-j(2 \pi k / N)}$ and $N=$ length $[x(n)]$. The FFT can be used for both quantifications of a noise problem and a vibration problem. Generally, the standardized one-third-octave band is adopted in the noise spectra analysis in order to obtain more detailed information.

\subsection{Rail Condition}

Wheel-rail roughness, especially rail corrugation, is the main source of vibration excitation for the interior noise of the metro vehicle. One of the most effective and economic countermeasures to prevent rail corrugation is rail grinding, especially before the operation. The field measurement of Metro line 14 of Guangzhou was conducted two weeks before its operation, and the rails were pre-grinded before its operation, as shown in Figure 1. Therefore, the influence of rail corrugation on the internal noise and the vibration of the subway vehicles could be considered as invariant during the field measurement. 


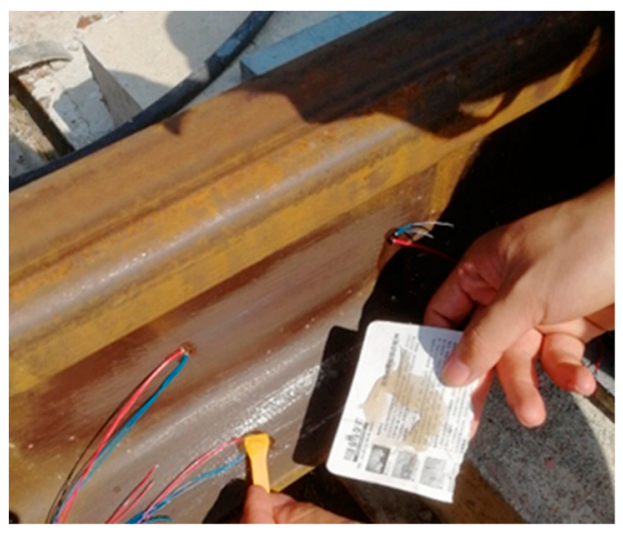

Figure 1. Photograph of rail condition.

\subsection{Continuous Rigid-Frame Box-Girder Bridge}

The running tests were conducted between overnight Dengcun station and Chicao station on metro line 14 in Guangzhou. The test section was an elevated metro line, which was mainly composed of $3 \times 40 \mathrm{~m}$ concrete continuous rigid-frame box-girder bridge, as illustrated in Figure 2 . The cross-sectional dimensions of the box girder are shown in Figure 3. The widths of the bridge deck and the bottom slab are $10 \mathrm{~m}$ and $2.4 \mathrm{~m}$, respectively. The height of the box-girder is about $2 \mathrm{~m}$. Two track systems are installed symmetrically on the bridge deck. The width of each track system is about $2.1 \mathrm{~m}$. The distance between the central lines of the girder and the track system is $2.05 \mathrm{~m}$.

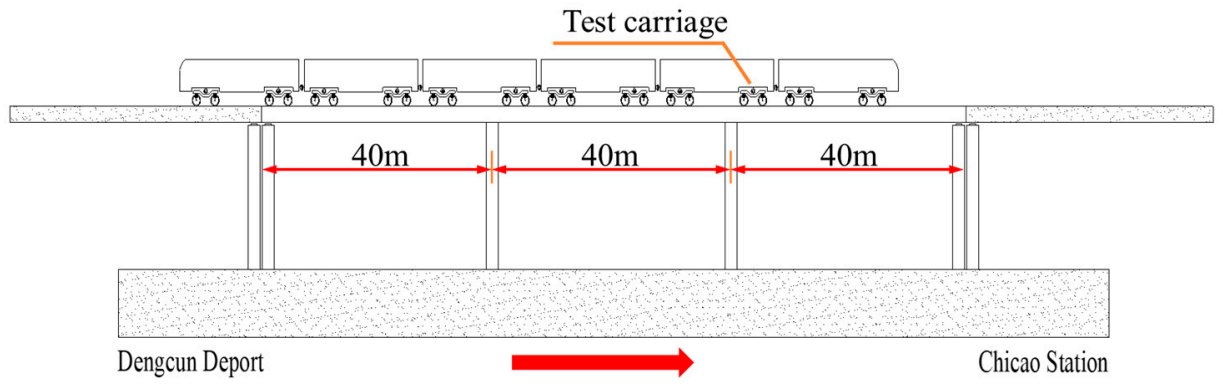

Figure 2. The schematic diagram of the running test.

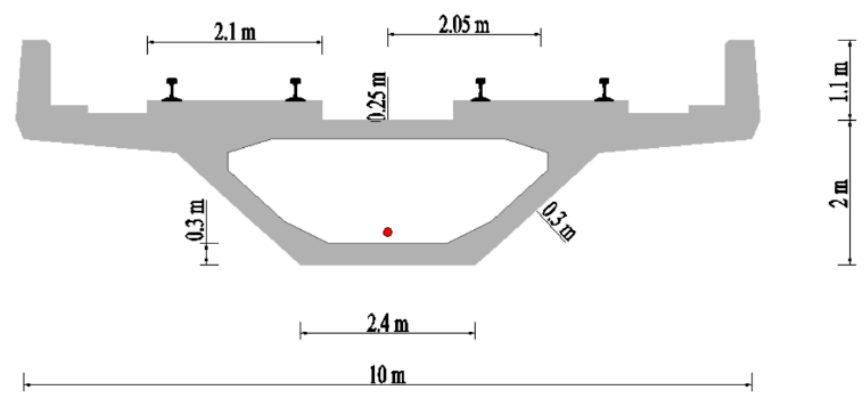

Figure 3. Schematic diagram of the box girder.

\subsection{Metro Vehicle}

The standard B-type metro train was used in the field test, which consists of four motor vehicles and two trailer vehicles, as illustrated in Figure 4 . The head and trail are trailers, and 4 motor vehicles were arranged between the two trailer cars. The width and length of each vehicle are $2.8 \mathrm{~m}$ and $19.98 \mathrm{~m}$, respectively. The maximum speed of the B-type metro train is designed to be $120 \mathrm{~km} / \mathrm{h}$. The measurement was conducted in the second passengers' carriage. Figures 5 and 6 demonstrate the 
installation positions of the microphones and accelerometers in the test vehicle. Eight microphones were placed along the centerline of the metro vehicle with distance at a distance of $2 \mathrm{~m}$ or $2.6 \mathrm{~m}$, as illustrated in Figure 5. All of these microphones were $1.2 \mathrm{~m}$ above the floor according to GB 14892 [31] and ISO 3381 [32]. Two microphones labeled N1 and N8 were installed at both ends of the vehicle. Two microphones labeled N2 and N7 were placed near the top of the bogie frame. The acoustic signals inside the test vehicle were collected by a 24-bit intelligent acquisition and signal processing system (type: INV3020). Four vibration measuring points (V1 to V4) were arranged on the floor directly below microphones labeled N2, N4, N6, and N8, respectively, as shown in Figure 5. There were four other vibration measuring points (V5-V8) installed at the wall panel with the same height of the microphone corresponding to four floor measuring points, respectively. The vibration signals of the metro vehicle at different speeds were measured by the SDI Model 2210 accelerometers $(4 \mathrm{mV} / \mathrm{g}$ sensitivity, $\pm 2 \mathrm{~g}$ full scale). The test speed was controlled to be $20 \mathrm{~km} / \mathrm{h}, 40 \mathrm{~km} / \mathrm{h}, 50 \mathrm{~km} / \mathrm{h}, 60 \mathrm{~km} / \mathrm{h}, 80 \mathrm{~km} / \mathrm{h}$, or $115 \mathrm{~km} / \mathrm{h}$. A sound level calibrator was adopted to calibrate all the microphones before and after each running test, and the deviation between the calibration before and after the tests was less than $0.5 \mathrm{~dB}$.

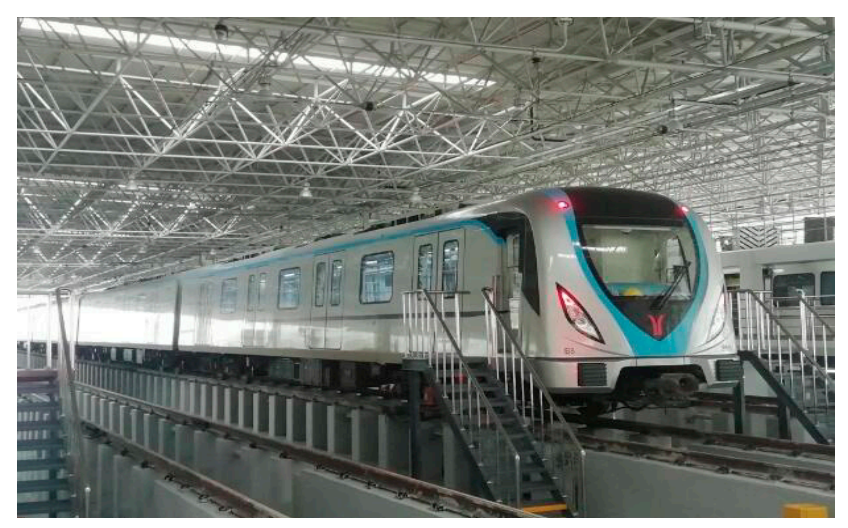

Figure 4. Photograph of the standard B-type metro train.

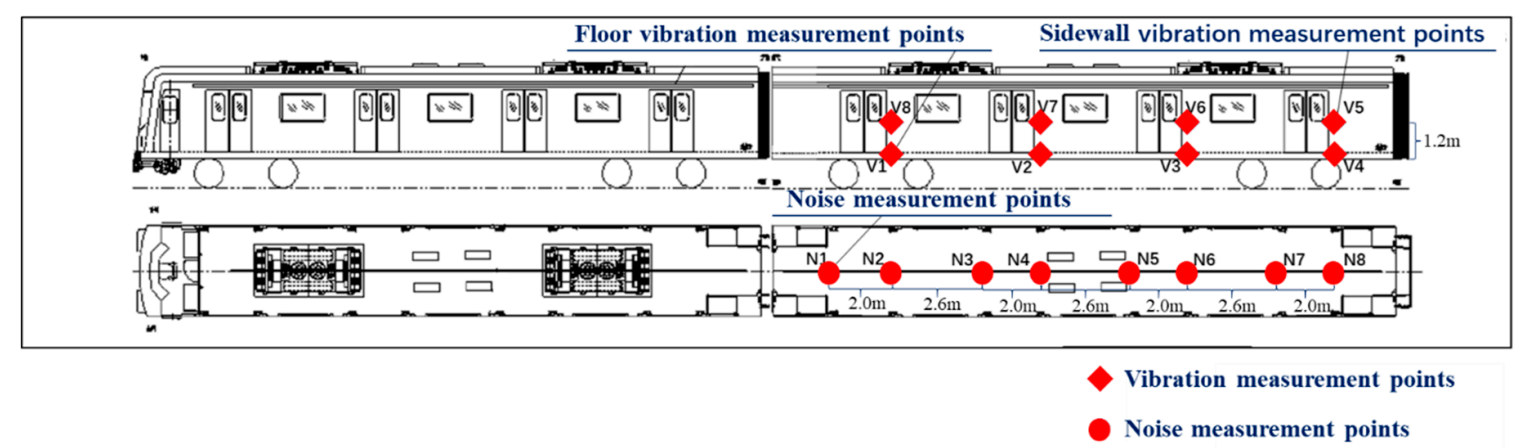

Figure 5. Layout of the noise and the vibration measurement points inside the vehicle. 


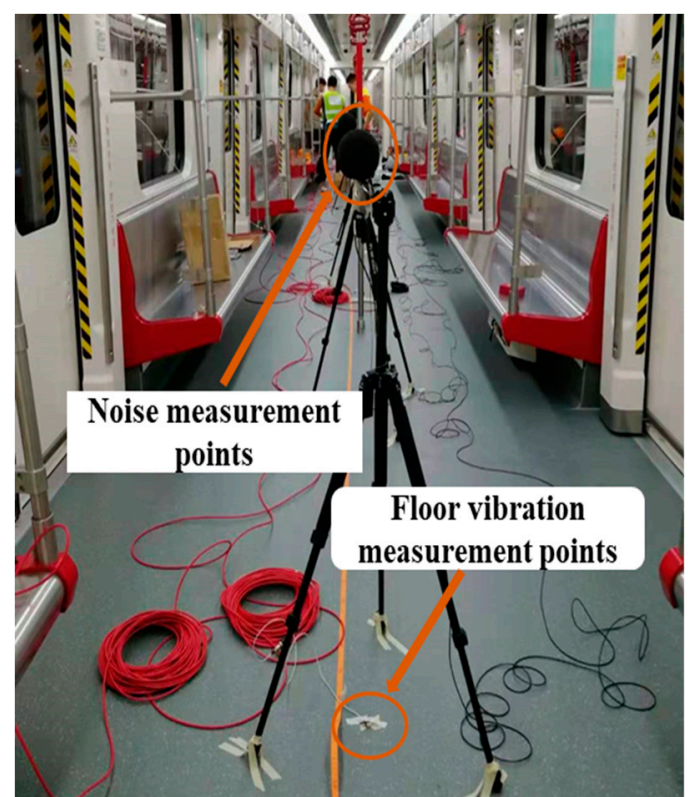

(a)

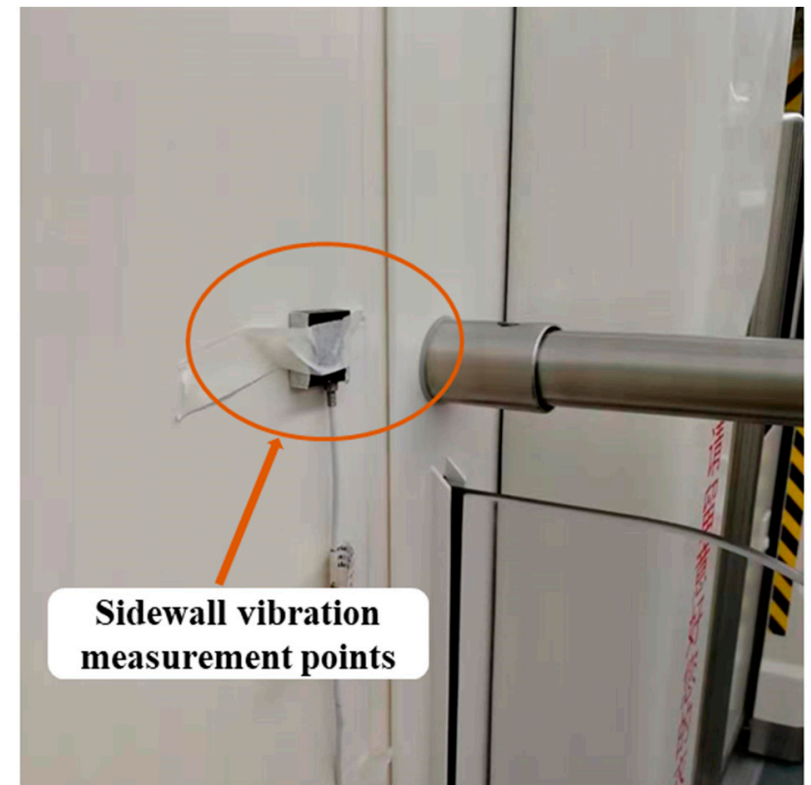

(b)

Figure 6. Photograph of equipment in the vehicle. (a) Noise measurement points and floor vibration measurement point; (b) sidewall vibration measurement point.

\section{Results and Discussion}

\subsection{Interior Noise Spectra of the Metro Vehicle}

According to the Noise Limit and Measurement for Trains of Urban Rail Transit standard [31] and referring to ISO 3381 standard [32], the noise measurement procedures satisfy the requirement that background noise is $10 \mathrm{~dB}$ lower than the interior noise. The A-weighted SPL has been widely used to evaluate the acoustic environment inside the train, and it has already been incorporated into some international and Chinese standards due to its consistency with the auditory characteristics of humans. The A-weighted SPL underestimates the noise below $1000 \mathrm{~Hz}$, while, the energy of the noise inside the metro vehicle was mainly focused on the middle and low frequency regions, as shown in Figure 7. It can be seen from Figure 8 that the phenomenon of neglect of low frequency noise in the A-weighted SPL seems to be more obvious with the increase of train speed. Figure 9 shows the total A-weighted SPL of all the measuring points and its corresponding linear SPL under the train speed of $115 \mathrm{~km} / \mathrm{h}$. The acoustic comfort inside the train may not be achieved even though the A-weighted SPL inside the train meets the requirements of these standards due to the underestimated impacts of the low-frequency component of the interior noise on people in the A-weighted SPL evaluation. Therefore, both the linear SPL and A-weighted SPL were adopted here in order to reveal the effects of A-weighted SPL's correction in the low frequency range on the interior noise. 

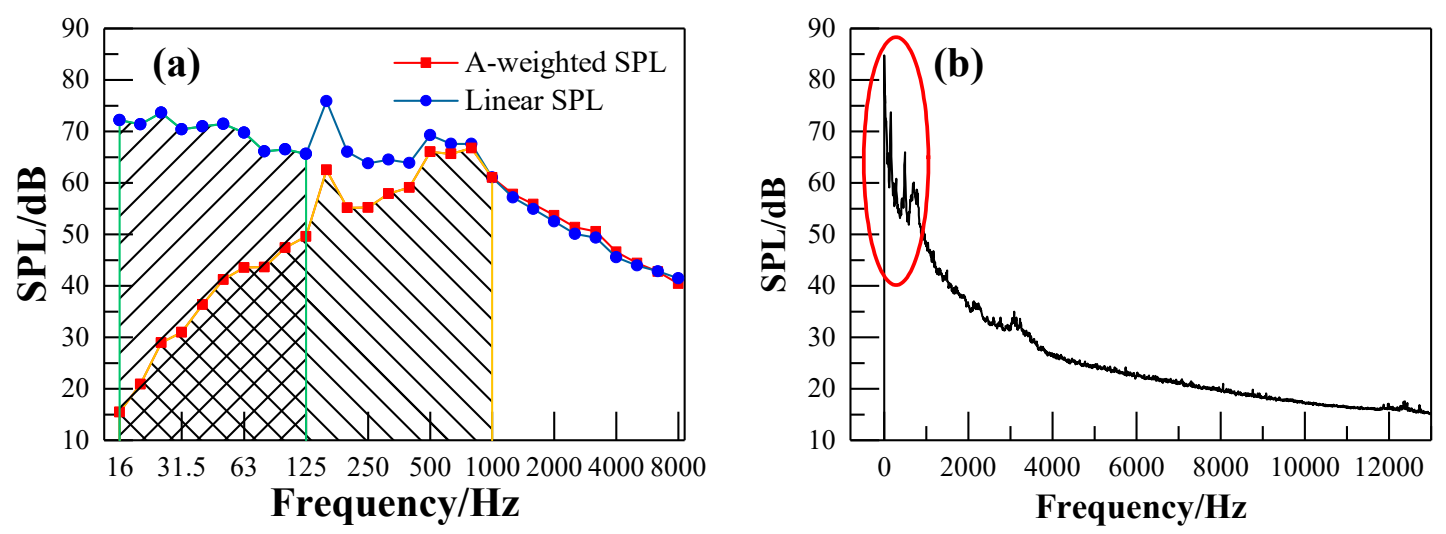

Figure 7. Interior noise at point $\mathrm{N} 1$ under the train speed of $50 \mathrm{~km} / \mathrm{h}$ : (a) one-third-octave band spectrum; (b) FFT spectrum.

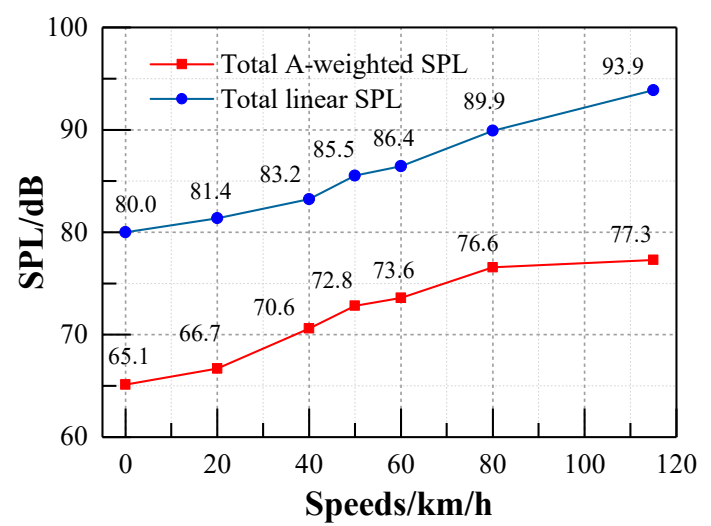

Figure 8. The total sound pressure levels at point N1 in respect of different train speeds.

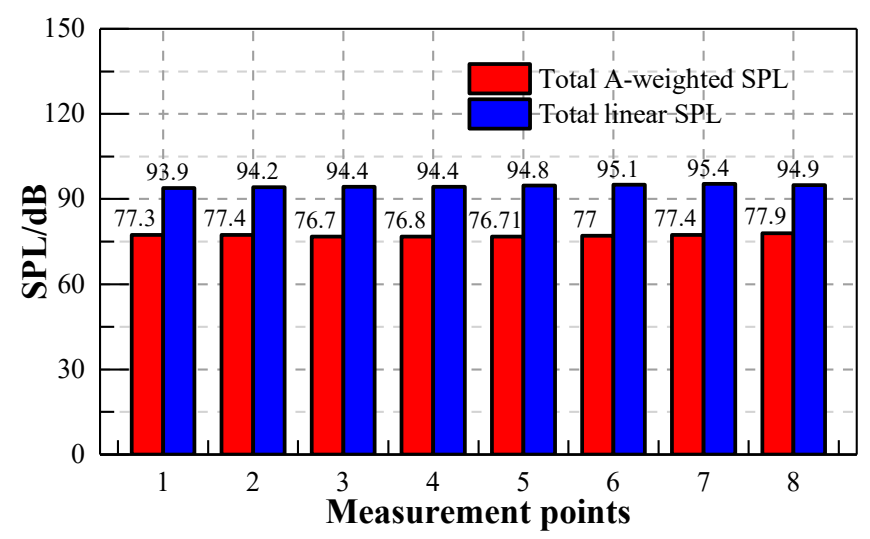

Figure 9. Comparison of total sound pressure levels using different methods with respect to different measuring points under the train speed of $115 \mathrm{~km} / \mathrm{h}$.

Since the combined effects of noise level and its frequency characteristics determines the acoustic environment of the vehicle, the total SPL and the spectrum characteristics of the interior noise are analyzed in this paper. The total SPL of each measuring point inside the vehicle with respect to different speeds is illustrated in Tables 1 and 2. It should be noted that $0 \mathrm{~km} / \mathrm{h}$ represents the interior noise of the test vehicle when it is stationary with the operation of the auxiliary equipment in the vehicle. The A-weighted SPL of the elevated metro vehicle cannot exceed the limitation of $75 \mathrm{dBA}$ [31]. It can be seen from Table 2 that the A-weighted SPL meets the limit requirements of no more than $75 \mathrm{dBA}$ when the vehicle speed is less than $70 \mathrm{~km} / \mathrm{h}$. When the vehicle speed exceeds $80 \mathrm{~km} / \mathrm{h}$, the A-weighted SPL 
does not satisfy the requirement. It indicates that countermeasures should be taken. The A-weighted SPL increases with the increasing of the train speed. Similar results of Figure 8 can also be found regarding other measuring points according to the results illustrated in Tables 1 and 2. It can also be observed that the total SPL of all these measurement points has little difference under the same speeds. This indicates the uniform distribution of the interior noise inside the vehicle. Table 1 also show that the SPL is above $85 \mathrm{~dB}$ when the train speed reaches $50 \mathrm{~km} / \mathrm{h}$. Generally, long-term exposure to noise above $85 \mathrm{~dB}$ may damage hearing [16]. Therefore, noise reduction countermeasures are necessary during the operation of a metro line with a relatively high train speed.

Table 1. Total linear sound pressure level (SPL) of each measuring point with respect to different train speeds $(\mathrm{dB})$.

\begin{tabular}{|c|c|c|c|c|c|c|c|}
\hline \multirow{2}{*}{ Points } & \multicolumn{7}{|c|}{ Speeds } \\
\hline & $0 \mathrm{~km} / \mathrm{h}$ & $20 \mathrm{~km} / \mathrm{h}$ & $40 \mathrm{~km} / \mathrm{h}$ & $50 \mathrm{~km} / \mathrm{h}$ & $60 \mathrm{~km} / \mathrm{h}$ & $80 \mathrm{~km} / \mathrm{h}$ & $115 \mathrm{~km} / \mathrm{h}$ \\
\hline N1 & 80.0 & 81.4 & 83.2 & 85.5 & 86.4 & 89.9 & 93.9 \\
\hline N2 & 79.5 & 80.6 & 82.9 & 85.1 & 86.2 & 89.8 & 94.2 \\
\hline N3 & 79.5 & 80.5 & 82.7 & 84.9 & 86.1 & 89.6 & 94.4 \\
\hline N4 & 79.4 & 80.5 & 82.7 & 84.9 & 86.1 & 89.5 & 94.4 \\
\hline N5 & 79.3 & 81.0 & 83.7 & 85.5 & 86.7 & 89.9 & 94.8 \\
\hline N6 & 80.0 & 81.3 & 83.7 & 85.8 & 86.9 & 90.2 & 95.1 \\
\hline N7 & 79.9 & 81.3 & 83.7 & 85.9 & 87.0 & 90.5 & 95.4 \\
\hline N8 & 79.1 & 81.0 & 83.9 & 85.7 & 86.7 & 90.1 & 94.9 \\
\hline
\end{tabular}

Table 2. Total A-weighted SPL of each measuring point with respect to different train speeds (dBA).

\begin{tabular}{|c|c|c|c|c|c|c|c|}
\hline \multirow{2}{*}{ Points } & \multicolumn{7}{|c|}{ Speeds } \\
\hline & $0 \mathrm{~km} / \mathrm{h}$ & $20 \mathrm{~km} / \mathrm{h}$ & $40 \mathrm{~km} / \mathrm{h}$ & $50 \mathrm{~km} / \mathrm{h}$ & $60 \mathrm{~km} / \mathrm{h}$ & $80 \mathrm{~km} / \mathrm{h}$ & $115 \mathrm{~km} / \mathrm{h}$ \\
\hline N1 & 65.1 & 66.7 & 70.6 & 72.8 & 73.6 & 76.6 & 77.3 \\
\hline N2 & 65.1 & 66.2 & 70.6 & 72.6 & 73.4 & 76.4 & 77.4 \\
\hline N3 & 64.8 & 66.2 & 70.0 & 72.1 & 72.8 & 75.7 & 76.7 \\
\hline N4 & 64.8 & 66.4 & 70.3 & 72.2 & 72.9 & 76.0 & 76.8 \\
\hline N5 & 65.0 & 66.8 & 70.3 & 72.4 & 73.0 & 76.0 & 76.7 \\
\hline N6 & 64.9 & 66.9 & 70.3 & 72.5 & 72.9 & 76.1 & 77.0 \\
\hline N7 & 64.4 & 67.1 & 70.6 & 72.8 & 73.4 & 76.3 & 77.4 \\
\hline N8 & 64.0 & 67.8 & 70.8 & 73.3 & 73.9 & 76.9 & 77.9 \\
\hline
\end{tabular}

Figures 10 and 11 show the interior noise spectrum corresponding to the train speeds of $50 \mathrm{~km} / \mathrm{h}$ and $115 \mathrm{~km} / \mathrm{h}$, respectively. It can be seen from Figures 10a and 11a that the noise energy is mainly concentrated in the frequency range of 31.5-1000 Hz. There are two obvious peaks located at almost the same frequency in both interior noise spectra, as illustrated in Figure 10. A similar result can also be observed in Figure 11. However, it should be noted that the first peak in Figure $11 \mathrm{~b}$ is not obvious. The first and second frequency peak in both Figures 10 and 11 center near $160 \mathrm{~Hz}$ and $800 \mathrm{~Hz}$, respectively. This indicates that the interior noise of the metro vehicle is mainly composed of low and medium frequency components, and the characteristics of the interior noise spectrum are not related to the train speed. The first and second frequency peaks may be generated by the vibration of the vehicle itself and wheel-rail noise, respectively. As the train speed increases, the value of the first peak gradually decreases and tends to disappear, while the value of the second peak tends to increase. The wheel-rail noise may dominate in the interior noise of the metro vehicle as the train speed increases. 

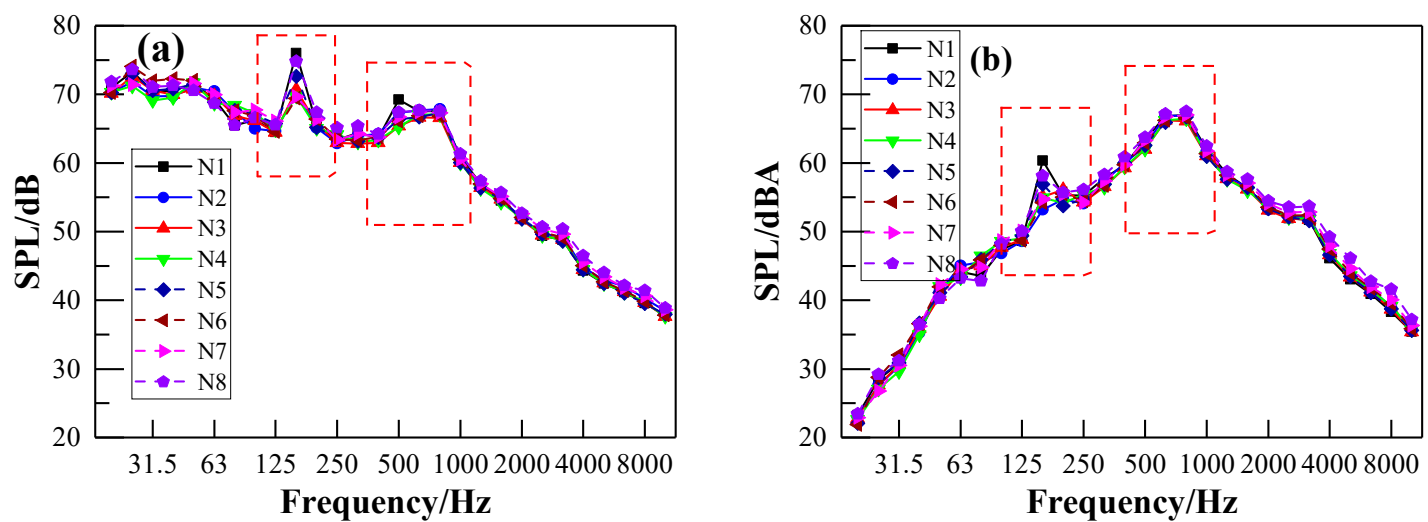

Figure 10. One-third-octave interior noise spectrum at different points (N1-N8) under the train speed of $50 \mathrm{~km} / \mathrm{h}$ : (a) linear SPL; (b) A-weighted SPL.
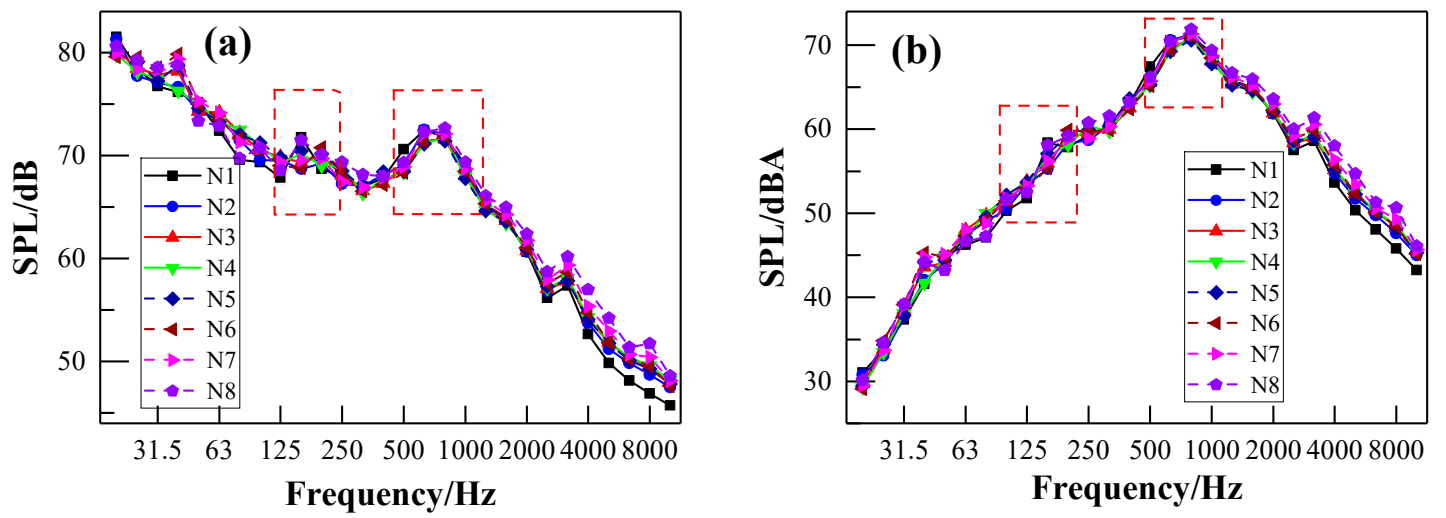

Figure 11. One-third-octave interior noise spectrum at different points (N1-N8) under the train speed of $115 \mathrm{~km} / \mathrm{h}$ : (a) linear SPL; (b) A-weighted SPL.

Figure 12 shows the interior noise spectrum of N2 with respect to different train speeds. It can be observed that the results of SPL are nearly independent of train speed when the train speed is less than $20 \mathrm{~km} / \mathrm{h}$, especially above $500 \mathrm{~Hz}$. This indicates that the interior noise is mainly caused by the auxiliary equipment of the vehicle when the train speed is under $20 \mathrm{~km} / \mathrm{h}$. Figure 13 also illustrates the dependence of the SPL on train speed. The SPL increases with increasing train speed. There are also two frequency peaks located around $160 \mathrm{~Hz}$ and $800 \mathrm{~Hz}$, as shown in Figure 12. The frequency peaks are nearly independent of train speed. It is worth noting that the first frequency peak appears when the train speed is $50 \mathrm{~km} / \mathrm{h}$. In the high-frequency range, the interior noise at $115 \mathrm{~km} / \mathrm{h}$ is at a relatively higher level than the interior noise at other train speeds, which may be due to the increase of aerodynamic noise. However, the curve of the noise spectrum decreases rapidly above $1250 \mathrm{~Hz}$ at these speeds due to the good sound insulation of the vehicle itself for high-frequency noise. 

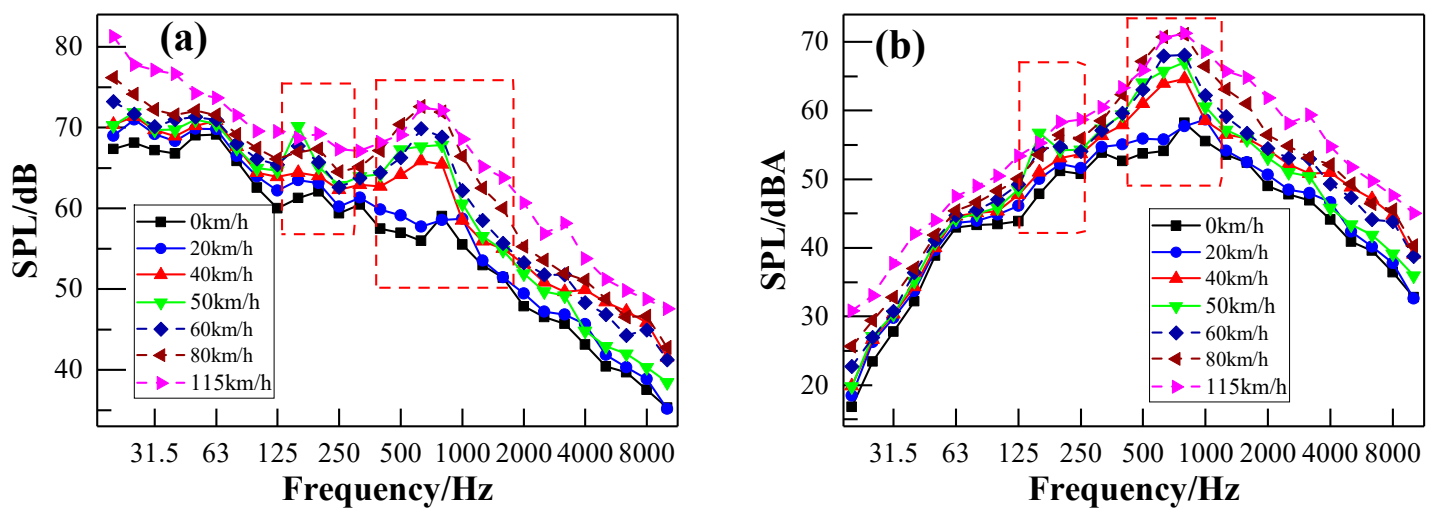

Figure 12. One-third-octave interior noise spectrum of point N2 under different train speeds: (a) linear SPL; (b) A-weighted SPL.

\subsection{Vibration Spectra of the Metro Vehicle}

The propagation path of noise in trains can be generally divided into the structural sound transmission and air sound transmission. The aim of vehicle vibration measurements is to reveal the relationship between the interior noise and the vibration of the metro vehicle. Figure 13a,b shows the vibration levels of the floor and sidewall, respectively, at a train speed of $50 \mathrm{~km} / \mathrm{h}$. Their corresponding frequency spectra using the FFT method are illustrated in Figure 14a,b, respectively. It can be observed that the vibration energy of the floor is mainly concentrated in the frequency range of 100-200 Hz. The frequency peak is located at $160 \mathrm{~Hz}$, which corresponds to the first frequency peak of the interior noise spectrum in Figure 10. This means that the low-frequency noise may be generated by the vibration of the floor. Figures 13a and 14a show that the vibration peak of the measuring points nearing the bogie frame (V1 and V4) are higher than the measuring points in the middle of the vehicle (V2 and V3). This means that the vibration of the bogie frame caused by the wheel-rail excitation may be directly transmitted to the vehicle and stimulate the vibration of the floor. It can be seen in Figure 14a that the sidewall has one more obvious frequency peak around $40 \mathrm{~Hz}$, apart from the same frequency peak as the floor. This kind of situation may be due to the secondary vibration of the sidewall caused by air sound. However, there is no significant difference in the vibration level of each measuring point around $40 \mathrm{~Hz}$ after applying the FFT transformation, as shown in Figure 14b. This may be the relatively low air-borne sound energy compared with the vibration energy of the bogie frame.
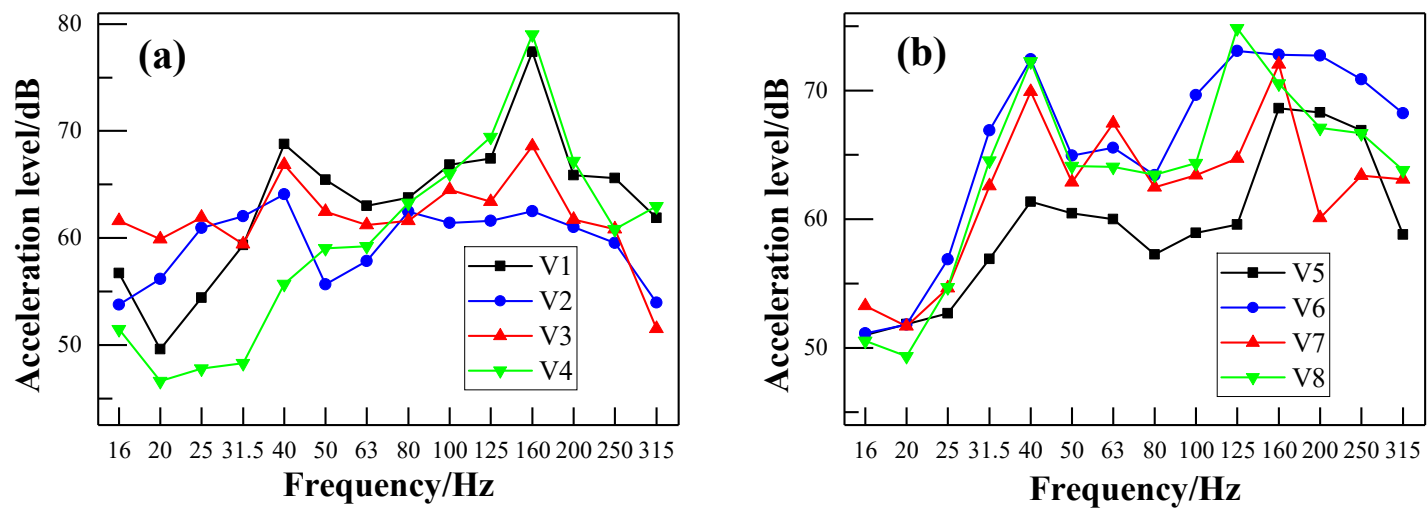

Figure 13. One-third-octave acceleration spectrum of different points at train speed of $50 \mathrm{~km} / \mathrm{h}$ : (a) measuring points of the floor; (b) measuring points of the sidewall. 

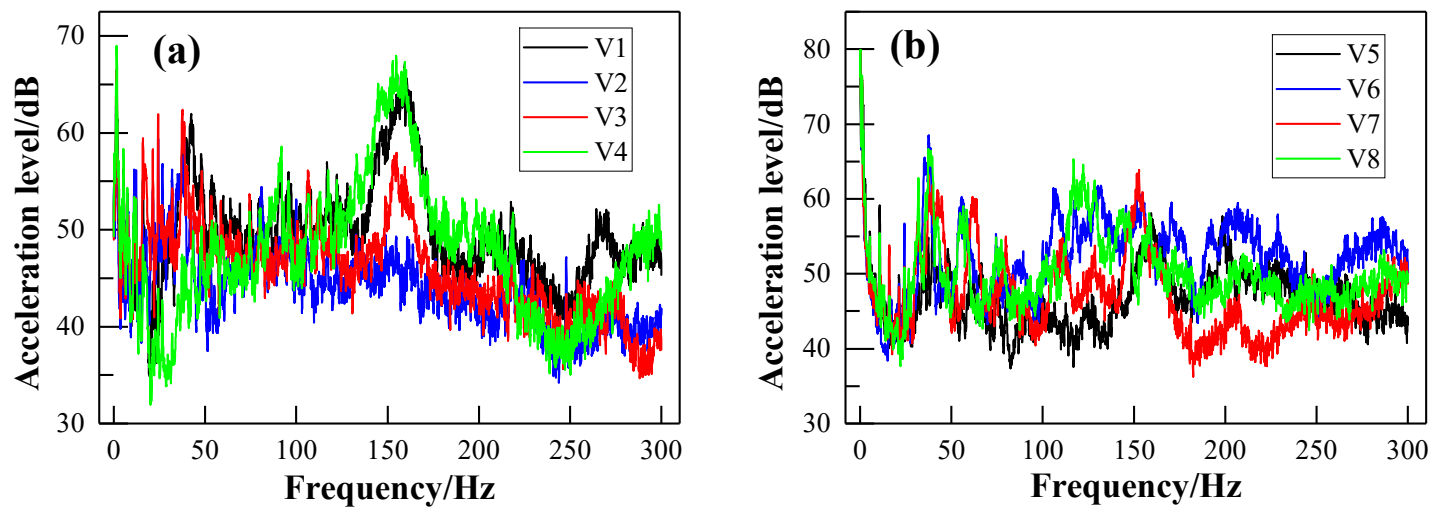

Figure 14. Fast Fourier transform (FFT) spectra of different points at train speed of $50 \mathrm{~km} / \mathrm{h}$ : (a) measuring points of the floor; (b) measuring points of the sidewall.

Figure $15 \mathrm{a}, \mathrm{b}$ shows the acceleration level of the floor measurement point V1 and the sidewall measurement point V8, respectively, with respect to different train speeds. Their corresponding frequency spectra using the FFT method are illustrated in Figure 16a,b, respectively. It can be seen from Figure 15 that both frequency peaks (around $40 \mathrm{~Hz}$ and $160 \mathrm{~Hz}$ ) of the floor and sidewall are independent of the train speed. However, the vibration acceleration level increases with the increase of the train speed in both the low-frequency and high- frequency range. However, the vibration acceleration level increases with the increase of the train speed in both the low-frequency range and the high-frequency range. The acceleration level difference between the train speeds of $40 \mathrm{~km} / \mathrm{h}$ and $80 \mathrm{~km} / \mathrm{h}$ is not obvious. However, the acceleration level is much higher when the train speed reaches $115 \mathrm{~km} / \mathrm{h}$. This may be the instability of the vehicle itself at a relatively higher speed. Figure 16a shows that the acceleration levels of the floor around the second frequency peak decrease with the increase of the train speed, which may be the rolling effects of the rail. It can be seen from Figure $16 \mathrm{~b}$ that the acceleration levels of the sidewall are nearly the same below $80 \mathrm{~Hz}$. Furthermore, the acceleration levels between train speeds are also not obviously different above $80 \mathrm{~Hz}$, except at $20 \mathrm{~km} / \mathrm{h}$. This indicates that the characteristics of the vehicle itself dominate the acceleration levels of the sidewall.
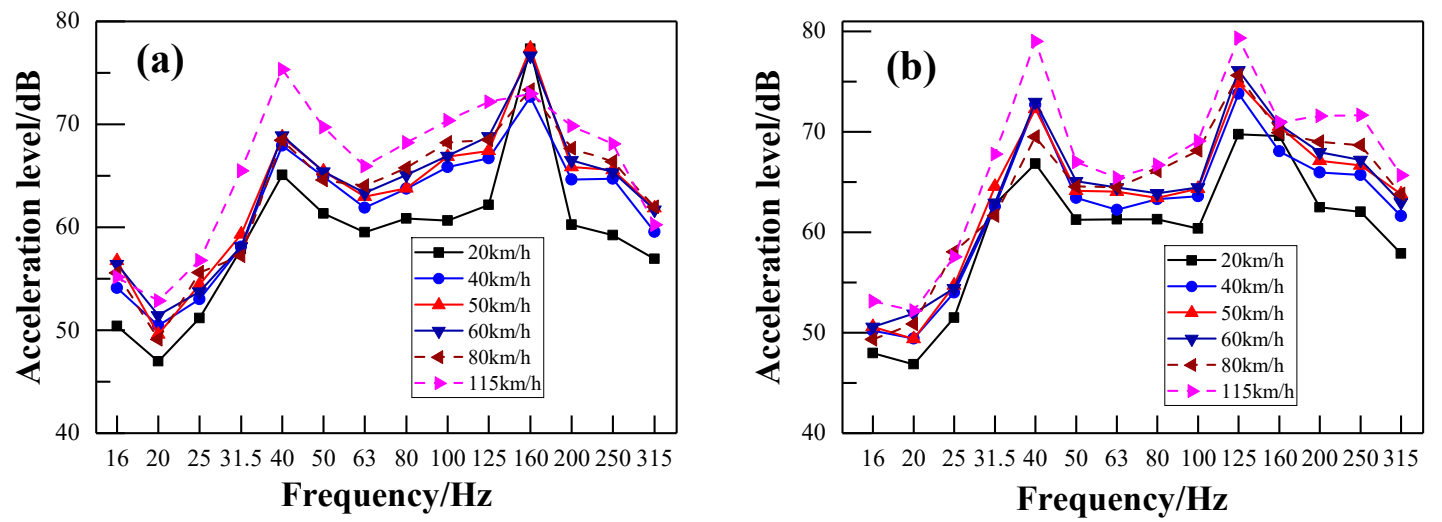

Figure 15. One-third-octave acceleration spectrum in respect of different train speeds: (a) measuring point V1 of the floor; (b) measuring point V8 of the sidewall. 

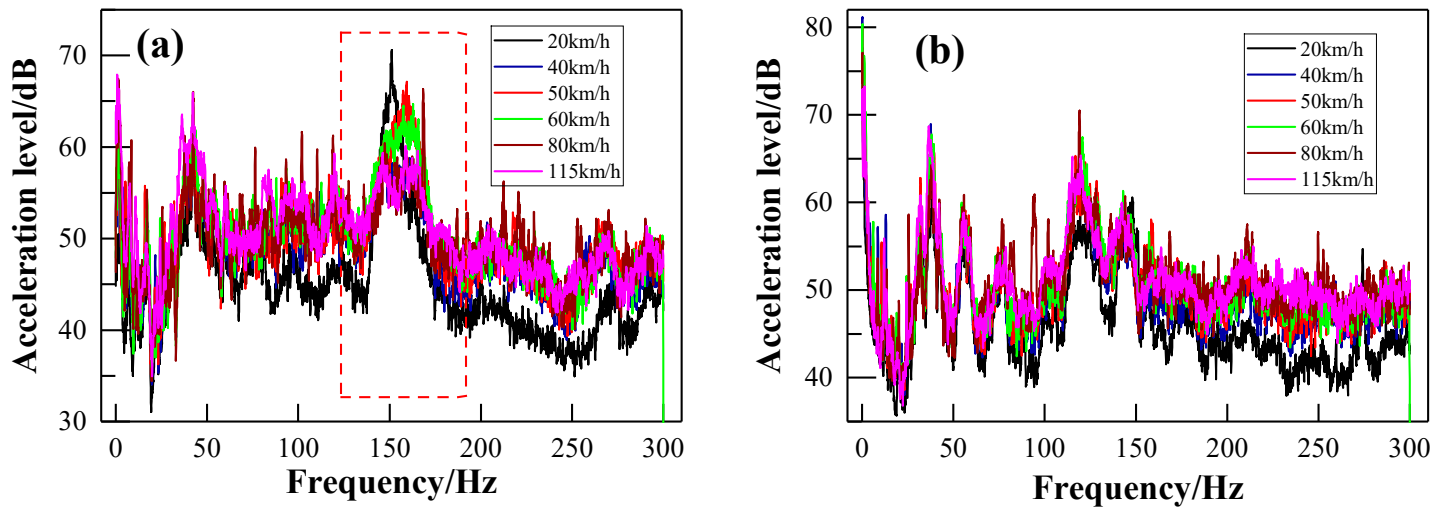

Figure 16. FFT spectra in respect of different train speeds: (a) measuring point V1 of the floor; (b) measuring point V8 of the sidewall.

\section{Conclusions}

Field experiments of the interior noise and vibration of a standard B-type metro train running on a viaduct were undertaken overnight on the Metro line 14 of Guangzhou (China). Both the A-weighted SPL and linear SPL were adopted to evaluate the measured interior noise signals. The FFT method was applied to measure vibrations of both the vehicle's floor and sidewall. The results show that the interior noise increases sharply with the increasing train running speed. However, the effects of the train's running speeds on the acceleration levels of the floor and sidewall are not apparent, especially in the range of $40-80 \mathrm{~km} / \mathrm{h}$. There are two obvious ranges $(125-250 \mathrm{~Hz}$ and $400-1000 \mathrm{~Hz}) \mathrm{in}$ the frequency domain of the interior noise. Their corresponding center frequencies are $160 \mathrm{~Hz}$ and $800 \mathrm{~Hz}$, respectively. These two frequency peaks are nearly independent of train speed. The spectrum analysis of the vehicle body vibration shows that the frequency peak of the floor corresponds to the first frequency peak of the interior noise spectrum. This indicates that the vibration of the floor contributes to the low-frequency noise components of the interior noise. There are two frequency peaks of the sidewall's acceleration level, around $40 \mathrm{~Hz}$ and $160 \mathrm{~Hz}$. The frequency peaks of the floor and sidewall are also independent of the train speed. This indicates that the characteristics of the vehicle itself dominate the frequency peaks of the acceleration levels of the floor and sidewall. The results show that different vibration reduction measures should be taken according to the characteristics of the floor and sidewall. Since field measurements of the interior noise and vibration of metro vehicles are quite rare in the literature, this paper can also provide an available data set and reference for researchers in further investigations.

Author Contributions: Conceptualization, L.Y. and C.C.; methodology, Y.Z. and X.H.; investigation, L.Y., Z.C., K.Y., and X.Z.; writing - original draft preparation, L.Y., Z.C., and C.C.; writing-review and editing, Y.Z. and X.H. All authors have read and agreed to the published version of the manuscript.

Funding: This research was funded by the National Key R\&D Program of China (Grant No. 2017YFB1201204) and the Natural Science Foundation of China (Grant Nos. 51508580, U1934209 and U1534206).

Acknowledgments: The authors gratefully acknowledge the support of National Natural Science Foundations of China (Grant Nos. 51508580, U1934209 and U1534206), the National Key R\&D Program of China (Grant No. 2017YFB1201204), and the Guangzhou Metro Group.

Conflicts of Interest: The authors declare no conflict of interest.

\section{References}

1. China Urban Rail Transit Association. Report on statistics and analysis of urban rail transit in 2018. Urban Rail Transit 2019, 38, 18-36.

2. Licitra, G.; Fredianelli, L.; Petri, D.; Vigotti, M.A. Annoyance evaluation due to overall railway noise and vibration in Pisa urban areas. Sci. Total Environ. 2016, 568, 1315-1325. [CrossRef] 
3. Bunn, F.; Zannin, P.H.T. Assessment of railway noise in an urban setting. Appl. Acoust. 2016, 104, $16-23$. [CrossRef]

4. Licitra, G.; Gallo, P.; Rossi, E.; Brambilla, G. A novel method to determine multiexposure priority indices tested for pisa action plan. Appl. Acoust. 2011, 72, 505-510. [CrossRef]

5. Cueto, J.L.; Petrovici, A.M.; Hernández, R.; Fernández, F. Analysis of the impact of bus signal priority on urban noise. Acta Acust. United Acust. 2017, 103, 561-573. [CrossRef]

6. Licitra, G.; Cerchiai, M.; Teti, L.; Ascari, E.; Bianco, F.; Chetoni, M. Performance Assessment of Low-Noise Road Surfaces in the Leopoldo Project: Comparison and Validation of Different Measurement Methods. Coatings 2015, 5, 3-25. [CrossRef]

7. Ruiz-Padillo, A.; Ruiz, D.P.; Torija, A.J.; Ramos-Ridao, Á. Selection of suitable alternatives to reduce the environmental impact of road traffic noise using a fuzzy multi-criteria decision model. Environ. Impact Assess. Rev. 2016, 61, 8-18. [CrossRef]

8. Gagliardi, P.; Teti, L.; Licitra, G. A statistical evaluation on flight operational characteristics affecting aircraft noise during take-off. Appl. Acoust. 2018, 134, 8-15. [CrossRef]

9. Iglesias-Merchan, C.; Diaz-Balteiro, L.; Solino, M. Transportation planning and quiet natural areas preservation: Aircraft overflights noise assessment in a national park. Transp. Res. Part D Transp. Environ. 2015, 41, 1-12. [CrossRef]

10. Michaud, D.S.; Feder, K.; Keith, S.E.; Voicescu, S.A.; Marro, L.; Than, J.; van den Berg, F. Exposure to wind turbine noise: Perceptual responses and reported health effects. J. Acoust. Soc. Am. 2016, 139, 1443-1454. [CrossRef] [PubMed]

11. Fredianelli, L.; Gallo, P.; Licitra, G.; Carpita, S. Analytical assessment of wind turbine noise impact at receiver by means of residual noise determination without the wind farm shutdown. Noise Control Eng. J. 2017, 65, 417-433. [CrossRef]

12. Bolognese, M.; Fidecaro, F.; Palazzuoli, D.; Licitra, G. Port noise and complaints in the north tyrrhenian sea and framework for remediation. Environments 2020, 7, 17. [CrossRef]

13. Fredianelli, L.; Nastasi, M.; Bernardini, M.; Fidecaro, F.; Licitra, G. Pass-by characterization of noise emitted by different categories of seagoing ships in ports. Sustainability 2020, 12, 1740. [CrossRef]

14. Gershon, R.R.M.; Qureshi, K.A.; Barrera, M.A.; Erwin, M.J.; Goldsmith, F. Health and safety hazards associated with subways: A review. J. Urban Health 2005, 82, 10-20. [CrossRef] [PubMed]

15. Münzel, T.; Sørensen, M.; Gori, T.; Schmidt, F.P.; Rao, X.; Brook, J.; Chen, L.C.; Brook, R.D.; Rajagopalan, S. Environmental stressors and cardio-metabolic disease: Part I-epidemiologic evidence supporting a role for noise and air pollution and effects of mitigation strategies. Eur. Heart J. 2017, 38, 550-556. [CrossRef]

16. Guski, R.; Schreckenberg, D.; Schuemer, R. WHO Environmental Noise Guidelines for the European Region: A Systematic Review on Environmental Noise and Annoyance. Int. J. Environ. Res. Public Health 2017, 14, 1539. [CrossRef]

17. Johnson, T.A.; Cooper, S.; Stamper, G.C.; Chertoff, M. Noise exposure questionnaire: A tool for quantifying annual noise exposure. J. Am. Acad. Audiol. 2017, 28, 14-35. [CrossRef]

18. Muzet, A. Environmental noise, sleep and health. Sleep Med. Rev. 2007, 11, 135-142. [CrossRef]

19. Dratva, J.; Phuleria, H.C.; Foraster, M.; Gaspoz, J.M.; Keidel, D.; Künzli, N.; Schindler, C. Transportation noise and blood pressure in a population-based sample of adults. Environ. Health Perspect. 2012, 120, 50-55. [CrossRef]

20. Babisch, W.; Beule, B.; Schust, M.; Kersten, N.; Ising, H. Traffic noise and risk of myocardial infarction. Epidemiology 2005, 16, 33-40. [CrossRef]

21. Bernardini, M.; Fredianelli, L.; Fidecaro, F.; Gagliardi, P.; Nastasi, M.; Licitra, G. Noise Assessment of Small Vessels for Action Planning in Canal Cities. Environments 2019, 6, 31. [CrossRef]

22. Thompson, D. Railway Noise and Vibration: Mechanisms, Modelling and Means of Control; Elsevier: Amsterdam, The Netherlands, 2008.

23. Eade, P.W.; Hardy, A.E.J. Railway vehicle internal noise. J. Sound Vib. 1977, 51, 403-415. [CrossRef]

24. Forssén, J.; Tober, S.; Corakci, A.C.; Frid, A.; Kropp, W. Modelling the interior sound field of a railway vehicle using statistical energy analysis. Appl. Acoust. 2012, 73, 307-311. [CrossRef]

25. Zheng, X.; Hao, Z.; Wang, X.; Mao, J. A full-spectrum analysis of high-speed train interior noise under multi-physical-field coupling excitations. Mech. Syst. Signal Process. 2016, 75, 525-543. [CrossRef] 
26. Dai, W.Q.; Zheng, X.; Luo, L.; Hao, Z.Y.; Qiu, Y. Prediction of high-speed train full-spectrum interior noise using statistical vibration and acoustic energy flow. Appl. Acoust. 2019, 145, 205-219. [CrossRef]

27. Shi, Y.; Xiao, Y.G.; Kang, Z.C. Interior noise investigation for a passenger room of a high speed train under wheel-rail excitation. J. Vib. Shock 2009, 28, 95-98.

28. Han, J.; Xiao, X.B.; Wu, Y.; Wen, Z.F.; Zhao, G.T. Effect of rail corrugation on metro interior noise and its control. Appl. Acoust. 2018, 130, 63-70. [CrossRef]

29. Li, L.; Thompson, D.; Xie, Y.S.; Zhu, Q.; Luo, Y.Y.; Lei, Z.Y. Influence of rail fastener stiffness on railway vehicle interior noise. Appl. Acoust. 2019, 145, 69-81. [CrossRef]

30. Fan, R.P.; Su, Z.Q.; Meng, G.; He, C.C. Application of sound intensity and partial coherence to identify interior noise sources on the high speed train. Mech. Syst. Signal Process. 2014, 46, 481-493. [CrossRef]

31. Noise Limit and Measurement for Train of Urban Rail Transit; GB 14892; Standardization Administration: Beijing, China, 2012. (In Chinese)

32. Railway Applications. Acoustics. Measurement of Noise Inside Railbound Vehicles; ISO 3381; ISO: Geneva, Switzerland, 2011.

33. Persson, K.; Björkman, M. Annoyance due to low frequency noise and the use of the dB (A) scale. J. Sound Vib. 1988, 127, 491-497. [CrossRef]

34. Torija, A.J.; Flindell, I.H.; Self, R.H. Subjective dominance as a basis for selecting frequency weightings. J. Acoust. Soc. Am. 2016, 140, 843-854. [CrossRef] [PubMed]

35. Seidman, M.D.; Standring, R.T. Noise and quality of life. Int. J. Environ. Res. Public Health 2010, 7, 3730-3738. [CrossRef] [PubMed]

36. Ma, K.W.; Wong, H.M.; Mak, C.M. A systematic review of human perceptual dimensions of sound: Meta-analysis of semantic differential method applications to indoor and outdoor sounds. Build. Environ. 2018, 133, 123-150. [CrossRef]

37. Ning, J.; Lin, J.H.; Zhang, B. Time-frequency processing of track irregularities in high-speed train. Mech. Syst. Signal Process. 2016, 66, 339-348. [CrossRef]

(C) 2020 by the authors. Licensee MDPI, Basel, Switzerland. This article is an open access article distributed under the terms and conditions of the Creative Commons Attribution (CC BY) license (http://creativecommons.org/licenses/by/4.0/). 